\title{
Barriers in organizing the Romanian firms in responsibility centers
}

\author{
Gina-Maria Moraru ${ }^{1, *}$ \\ ${ }^{1}$ Lucian Blaga University of Sibiu, Engineering Faculty, Industrial Engineering and Management \\ Department, 4 Emil Cioran St, 550025 Sibiu, Romania
}

\begin{abstract}
In the current turbulent business environment, the big and medium enterprises must organize their activity in order to face new challenges. One of the organizational forms that can stimulate the performances of the firms is the one in responsibility centers. This paper addresses the issue of the responsibility centers starting from the possibility of using benchmarking before and after the implementation of this organizational form. After highlighting the advantages of the responsibility centers, we presented a study made in Romanian big and medium organizations, regarding the barriers in the design and implementation of this organizational form. The main causes that determine Romanian managers to avoid the organization in responsibility center were analyzed through several techniques specifically used in quality management. After this analyze, we proposed several measures for overcoming these barriers.
\end{abstract}

\section{Introduction}

One of the modern ways of organizing large or medium-sized companies is the management center, called responsibility center by some authors. In [1], the two designations are used interchangeably. In essence, the company's budget is divided into sub-budgets corresponding to each division that consists of a control center, characterized by the following features:

- Setting up a management center is based on a field of activity, on a particular activity or process within the company;

- One or several specific missions for each center, substantiated by clear-cut quantitative and qualitative targets;

- The existence of a stock of available resources, necessary to reach these objectives;

- A center manager;

- All areas of activity within the company are covered by the management centers, but with no overlapping activities;

- The ability of the center to adjust to the changes in the business environment (called "selfstabilization" in [1], [2]);

- The ability of the center to develop its own stable sub-structures (called "selforganization" in [1], [2]).

${ }^{*}$ Corresponding author: gina.moraru@ulbsibiu.ro 


\section{Advantages and disadvantages of the responsibility centers}

Among the managerial advantages of this type of organization, we mention the technical role of the budgets, which confers the organization around management centers the capability of establishing the foresight management of the company, and the behavioral role of the budgets, allowing the empowerment and motivation of the human resource in the long term [1].

To identify the disadvantages of this form of organization, we must first correlate the functioning of this structure, the type of organizational culture that it fosters [3] and the way in which it stimulates the use of production factors. At first glance, the functioning seems to be ideal, as any process irregularities can be detected and corrected at an early stage. We are informed of the exact way in which the tangible resources of the company are employed [4], by whom and to what effect. This "mechanism" of the management centers seems to work flawlessly, with clock-like precision. The organizational culture stimulated within the company is based on order, discipline, respect, waste avoidance and, above all, efficiency. Essentially, quantitative results are particularly important in this form of organization, but qualitative ones are usually left in the background. The freedom of the individual is subject to be limited by figures that mark actual achievements, and this leads to the risk of suppressing change initiatives and creativity acts.

By analyzing in detail a company organized around management centers (Fig. 1), we can notice that a clear-cut delineation of these centers and of their targets raises barriers to the possible creative interaction between groups and individuals belonging to different centers. Creativity is a new factor of production mainly used by research and development teams (Fig. 1). In this type of organization, production as well as the personnel and marketing functions have many duties related to material and financial purposes but very few creative duties. The creative results of the research and development departments usually cross the other departments, without gaining further innovation.

Another potential danger caused by this form of organization is the exacerbation of the importance of purely financial values. For instance, by tracking the financial profitability of the company, the management may adopt measures which are harmful to the natural environment, but which improve the operation of the "mechanism" of management centers, and increase their economic indicators and momentary customer satisfaction.

However, we believe that the primary disadvantage of this form of organization is the danger of the excessive branching of the company's activities, especially those generating profit. Similar design, production, accounting, etc. departments, carrying out almost identical activities, yet working at full capacity only for short periods of time, may unnecessarily appear within different management centers. Their operation in parallel may prove to be - in the long run - unprofitable or insufficiently profitable for the organization, even if it is profitable for each individual center.

I deliberately set aside for the final section of this brief analysis a few of the advantages of the organization around management centers, advantages that are directly or indirectly related to the possibility of using regular benchmarking (Fig. 1) in order to improve the results of the organization and all changes in its system (circular dotted arrow in Fig. 1). For a start, each center provides, through its self-regulation mechanism, effective and permanent management. From the perspective of management planning, the organization around management centers supports the efficient implementation and running of the operational plans within its links; thus, a context that is favorable to the performance management is created. In order for budgetary procedures to connect the strategy to shortterm actions, benchmarking - especially internal - is an extremely effective and useful solution available to center managers and to the senior management of the company, facilitating the strategic management of the organization. Once the three levels of control 
are correlated (management, performance and strategic), the optimal corrections needed in the system are easier to find.

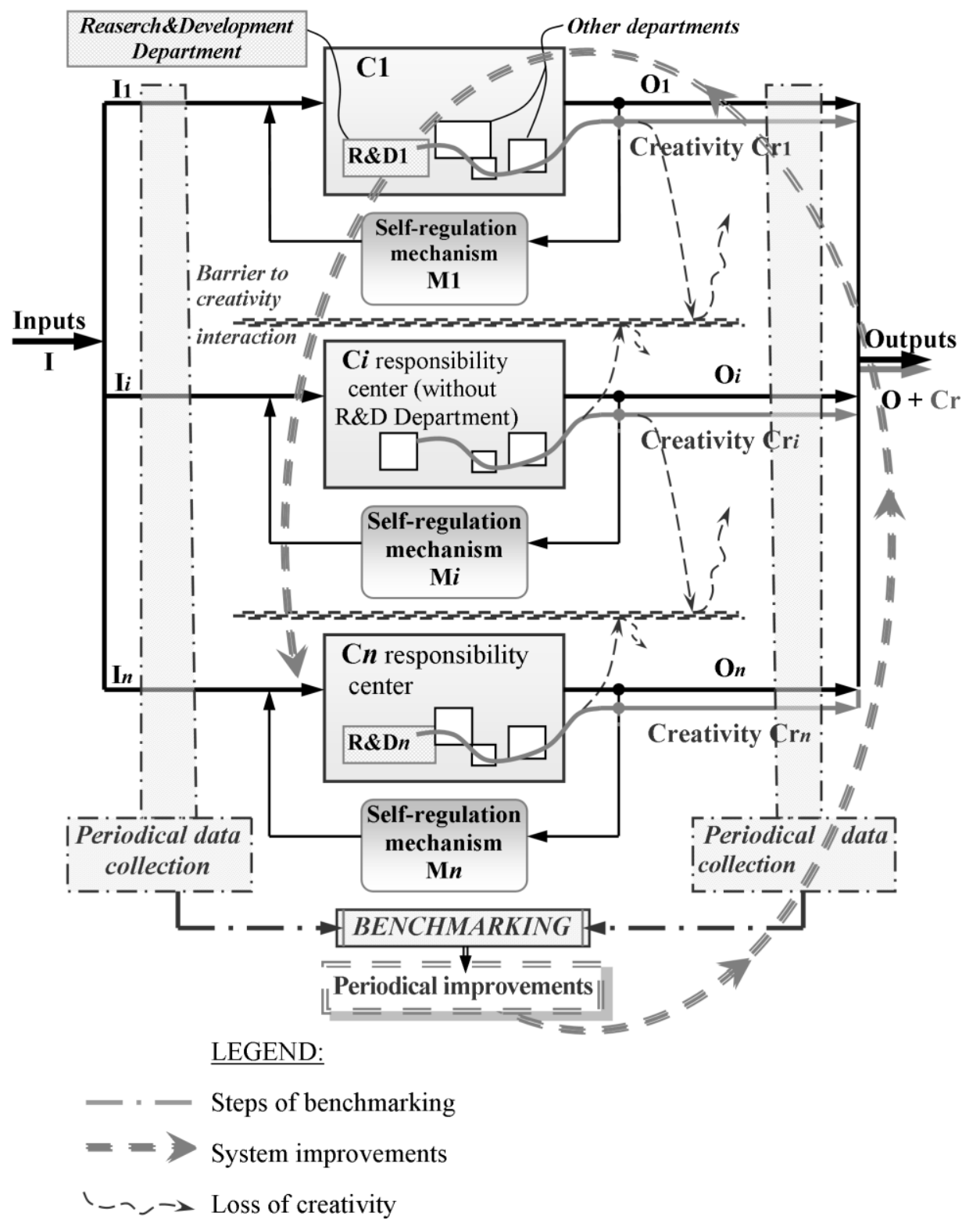

Fig. 1. Benchmarking in a company that is organized in responsibility centers

Another principle necessary for the proper functioning of management centers needs to be observed: correctly motivating the employees, within the framework of a partially decentralized human resource management. Costache Rusu and Monica Voicu point out: "The methods of motivation within the management center vary and depend largely on the competence and creativity of the one who devises them" [2]. This reality holds one of the most significant strengths of the organization around management centers, which can also constitute one of its most important weaknesses: getting the most out of individual 
creativity by every manager, with or without the interaction of these individual creativities at group level [5]. The system is successful in the long run only if all managers creatively work together, destroying the barriers between the centers (Fig. 1).

\section{Study in Romanian companies}

In order to discover the causes who determine the Romanian managers to reject the firm reorganization in responsibility centers, we firstly made a focus-group with 6 members of the staff from large and medium companies/enterprises and 3 academics, specialists in finance-accounting and/or management. During debate, we selected the most frequently mentioned causes of the problem. These 25 causes are represented in the Ishikawa diagram in Figure 2. They were grouped by the 9 participants to the focus-group in 6 main categories: materials, methods, people, environment, equipments and money. The participants assessed the severity of these causes with 1 point for a low severity, 3 points for a medium severity and 9 points for a high severity (see Table 1).

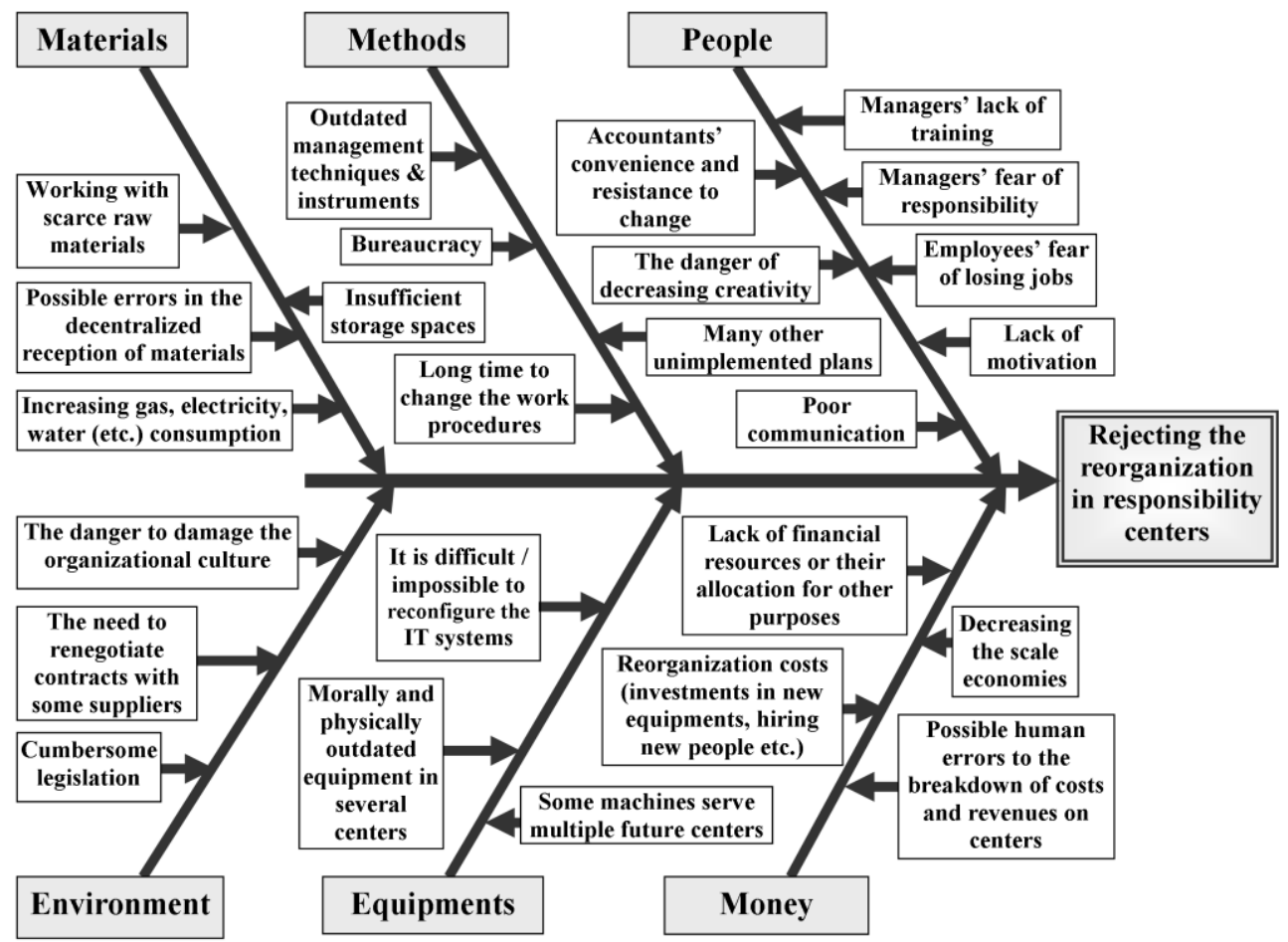

Fig. 2. Causes of rejecting the firm reorganization in responsibility centers - the Ishikawa diagram

Secondly, we gave questionnaires to 33 managers and specialists in various large and medium enterprises in Romanian industry. We asked respondents to mark any of the 25 issues in the questionnaire, if they consider them potential causes of the problem. We presented in table 1 the scores accorded by the respondents to the analyzed causes of the problem, in descending order. Using these results, we built the Pareto chart of the main barriers that prevent the organization of Romanian firms in responsibility centers (Fig. 3).

Thirdly, we proposed the following measures for overcoming the first 6 barriers: achieving a sustainable financial plan for at least 3 years, clarifying to the employees their importance in all changes made in the company and the management intention for keeping them in the firm, making periodical training for managers, finding ways to respect deadlines and 
developing of collaborative programs between centers and departments for enhancing the creativity in the firm.

Table 1. Scores accorded by the respondents to the causes of problem.

\begin{tabular}{|c|c|c|c|c|c|c|}
\hline Code & Cause & Frequency & Severity & Score & Percentage & $\begin{array}{l}\text { Cumulative } \\
\text { percentage }\end{array}$ \\
\hline Money 1 & $\begin{array}{l}\text { Reorganization costs (new } \\
\text { equipments, hiring people etc.) }\end{array}$ & 32 & 9 & 288 & $19.20 \%$ & $19.20 \%$ \\
\hline People 1 & Employees' fear of losing jobs & 29 & 9 & 261 & $17.40 \%$ & $36.60 \%$ \\
\hline People 2 & Managers' lack of training & 22 & 9 & 198 & $13.20 \%$ & $49.80 \%$ \\
\hline Money 2 & $\begin{array}{l}\text { Lack of financial resources or their } \\
\text { allocation for other purposes }\end{array}$ & 19 & 9 & 171 & $11.40 \%$ & $61.20 \%$ \\
\hline Methods 1 & Many other unimplemented plans & 18 & 9 & 162 & $10.80 \%$ & $72.00 \%$ \\
\hline People 3 & $\begin{array}{l}\text { The danger of decreasing } \\
\text { creativity }\end{array}$ & 12 & 9 & 108 & $7.20 \%$ & $79.20 \%$ \\
\hline Methods 2 & $\begin{array}{l}\text { Outdated management techniques } \\
\& \text { instruments }\end{array}$ & 18 & 3 & 54 & $3.60 \%$ & $82.80 \%$ \\
\hline People 4 & $\begin{array}{l}\text { Accountants' convenience and } \\
\text { resistance to change }\end{array}$ & 14 & 3 & 42 & $2.80 \%$ & $85.60 \%$ \\
\hline People 5 & Lack of motivation & 12 & 3 & 36 & $2.40 \%$ & $88.00 \%$ \\
\hline Equipments 1 & $\begin{array}{l}\text { Morally and physically outdated } \\
\text { equipment in several centers }\end{array}$ & 3 & 9 & 27 & $1.80 \%$ & $89.80 \%$ \\
\hline Environment1 & Cumbersome legislation & 21 & 1 & 21 & $1.40 \%$ & $91.20 \%$ \\
\hline People 6 & Managers' fear of responsibility & 2 & 9 & 18 & $1.20 \%$ & $92.40 \%$ \\
\hline Methods 3 & Bureaucracy & 17 & 1 & 17 & $1.13 \%$ & $93.53 \%$ \\
\hline Equipments 2 & $\begin{array}{l}\text { It is difficult or impossible to } \\
\text { reconfigure the IT systems }\end{array}$ & 5 & 3 & 15 & $1.00 \%$ & $94.53 \%$ \\
\hline Materials 1 & Insufficient storage spaces & 4 & 3 & 12 & $0.80 \%$ & $95.33 \%$ \\
\hline Methods 4 & $\begin{array}{l}\text { It is difficult to change the work } \\
\text { procedures }\end{array}$ & 12 & 1 & 12 & $0.80 \%$ & $96.13 \%$ \\
\hline People 7 & Poor communication & 11 & 1 & 11 & $0.73 \%$ & $96.87 \%$ \\
\hline Environment2 & $\begin{array}{l}\text { The need to renegotiate contracts } \\
\text { with some suppliers }\end{array}$ & 3 & 3 & 9 & $0.60 \%$ & $97.47 \%$ \\
\hline Money 3 & Decreasing the scale economies & 3 & 3 & 9 & $0.60 \%$ & $98.07 \%$ \\
\hline Materials 2 & $\begin{array}{l}\text { Possible errors in the decentralized } \\
\text { reception of materials }\end{array}$ & 2 & 3 & 6 & $0.40 \%$ & $98.47 \%$ \\
\hline Materials 3 & Working with scarce raw materials & 2 & 3 & 6 & $0.40 \%$ & $98.87 \%$ \\
\hline Equipments 3 & $\begin{array}{l}\text { Some machines serve multiple } \\
\text { future centers }\end{array}$ & 6 & 1 & 6 & $0.40 \%$ & $99.27 \%$ \\
\hline Money 4 & $\begin{array}{l}\text { Human errors to the breakdown of } \\
\text { costs and revenues on centers }\end{array}$ & 2 & 3 & 6 & $0.40 \%$ & $99.67 \%$ \\
\hline Environment3 & $\begin{array}{l}\text { The danger to damage the } \\
\text { organizational culture }\end{array}$ & 1 & 3 & 3 & $0.20 \%$ & $99.87 \%$ \\
\hline Materials 4 & $\begin{array}{l}\text { Increasing gas, electricity, water } \\
\text { (etc.) consumption }\end{array}$ & 2 & 1 & 2 & $0.13 \%$ & $100.00 \%$ \\
\hline
\end{tabular}




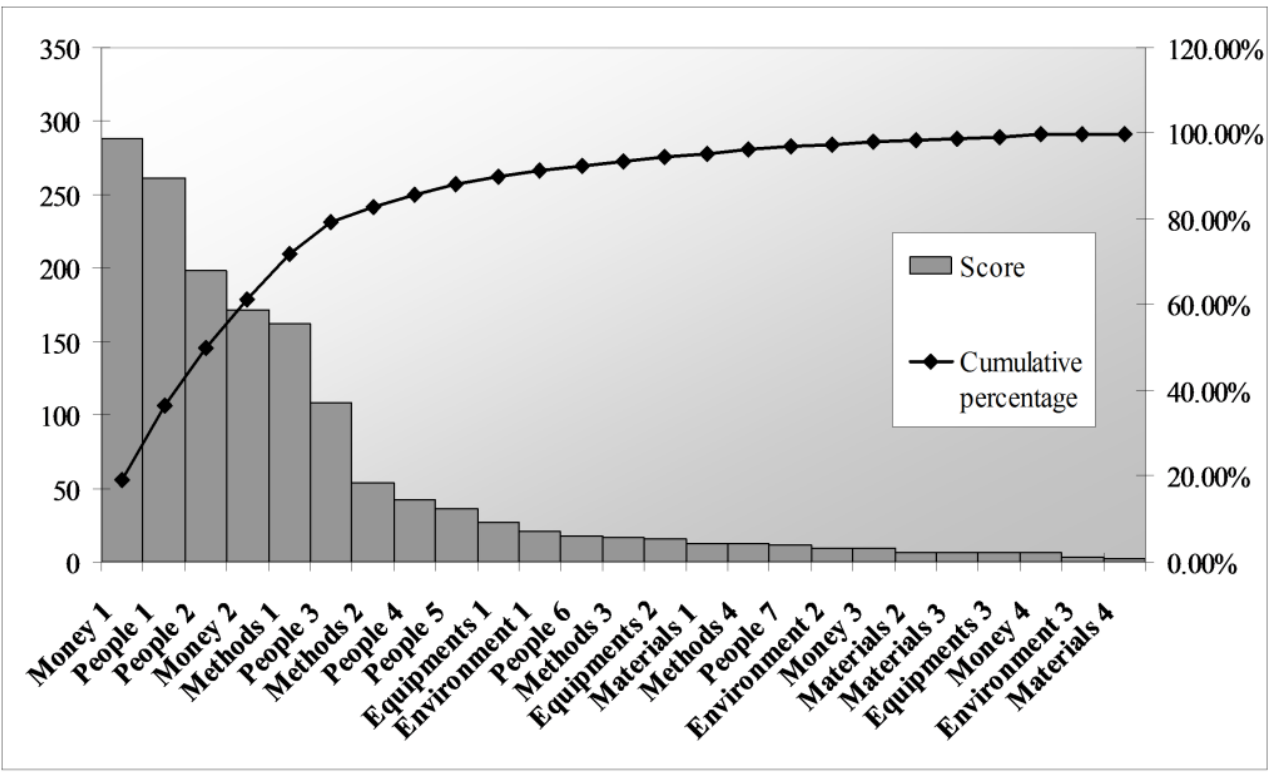

Fig. 3. Barriers in organizing Romanian firms in responsibility centers - the Pareto chart

\section{Conclusions}

One of the organizational forms that can stimulate the performances of the big and medium enterprises is the one in responsibility centers. The most difficult to overcome barriers for reorganizing the Romanian firms in responsibility centers are: the costs of this process, the employees' fear of losing their jobs, the managers' lack of training, the lack of financial resources or their allocation for other purposes, the existence of other unimplemented plans and the danger of decreasing creativity in the firm.

In order to reorganize the big and medium companies in responsibility centers, managers have to:

- Achieve a sustainable financial plan for at least 3 years;

- Clarify to the employees their importance in all organizational changes and the management intention for keeping them in the firm;

- Make periodical training for managers, in accounting and other economic fields;

- Find ways to respect the deadlines for all ongoing programs;

- Implement collaborative programs between centers and departments for enhancing the creativity in the firm.

The future research regarding the possibilities of reorganizing the big and medium firms in responsibility centers will focus on several factors that customize this process from one case to another [4]:

- The size and complexity of the company and the specificity of the processes, according to its industrial field;

- The components of the strategy and their correlation with the interests of owners;

- The financial situation of the organization in correlation with the technical endowment (of the firm and of each department) and with the intellectual capital [6];

- The organizational culture, its elements and availability for changes;

- The complexity and characteristics of human resources, including their professional aspirations. 
This work was supported by the grant LBUS-IRG-2016-02, co-financed by the Lucian Blaga University of Sibiu, Romania.

\section{References}

1. O. Nicolescu, I. Plumb et al. (coordinators), F. Badea (author of §1.3), Abordari moderne in managementul si economia organizatie 2, §1.3, 39-57 (Ed. Economica, Bucharest, 2003)

2. C. Rusu, M. Voicu, Managementul pe baza centrelor de responsabilitate (Ed. Economica, 2001)

3. H. Bouquin, Comtabilite de gestion (Economica, Paris, 2004)

4. C. Obreja, Annals of "Stefan cel Mare" Univ. Suceava. Fasc. Faculty of Ec. \& Public Adm. 8, $162-169(2008)$

5. G.M. Moraru, Creativity Management and Benchmarking Promoting Performance and Competitiveness in Modern Organizations, PhD Thesis, "Lucian Blaga" University of Sibiu (2011, unpublished)

6. L.M. Gogan, A. Draghici, Proceedings of The $6^{\text {th }}$ Int. Conf. MSE 2013, Sibiu, $461-464$ (2013) 